\title{
Helping Veterans and Their Families Fight On!
}

\author{
Megan Hazle \\ Sherrie L. Wilcox \\ Anthony M. Hassan
}

\begin{abstract}
This new generation of veterans is coming home to families, friends, employers, and communities that likely do not understand military culture, nor the effects that military service and reintegration have on a veteran's life, leading to the next war - the Reintegration War. Military servicemembers, veterans, and their families face challenges within the Reintegration War that are different from their civilian counterparts and are complicated by military-specific circumstances. In order to more effectively and efficiently address the challenges servicemembers, veterans, and their families face, we need to work together in a comprehensive effort. Strategies are presented to help win the Reintegration War and ease the transition for servicemembers, veterans, and their families.
\end{abstract}

Keywords: Family members, military, reintegration, servicemembers, Veterans

\section{THE NEXT WAR}

The current wars in Afghanistan and Iraq have collectively proved to be the longestrunning conflicts in the history of the United States. According to U.S. Census data, approximately 2.3 million men and women have served in the U.S. military during this period (i.e., post-9/11) — a significant number that nonetheless only represents about $1 \%$ of the country's population (U.S. Census Bureau, 2010). It is even more alarming that an estimated 2 million deployments have occurred during these wars (Belasco, July 2, 2009), nearly enough for all military personnel to have been deployed at least once, although multiple deployments are more common. With the drawdown of U.S. military involvement in Afghanistan and Iraq, a large influx of military personnel will soon return home, separate from military service, and will need to adjust to life outside the wire. This new generation of veterans is coming home to families, friends, employers, and communities that likely do not understand military culture, nor the effects that military service and reintegration have on a veteran's life, leading to the next war - the Reintegration War.

In the Reintegration War, some of the challenges confronting veterans and their families are significant and indisputable, but not always visible (Institute of Medicine, 2010; Tanielian et al., 2008). Popular media typically focus on the highs and lows of military and veteran life, such as troop homecomings and military family reunions, war casualties, or suicides, and overlook the everyday struggles of reintegration that veterans and their families face. Although many veterans grapple with physical or psychological wounds, the scope of challenges is broader and deeper than most realize. Whatever their reasons for entering military service, or the politics behind the conflicts, this is a high-risk population in need and we all have a moral duty to support and care for them. A

Megan Hazle, MA, is a Project Manager, Sherrie L. Wilcox, Ph.D., CHES, is Research Assistant Professor, and Anthony M. Hassan, Ed.D., LCSW, is a Clinical Associate Professor and Director, all at the Center for Innovation and Research on Veterans \& Military Families (CIR), School of Social Work, University of Southern California.

Copyright @ 2012 Advances in Social Work Vol. 13 No. 1 (Spring 2012), 229-242 
community-wide front is required to combat the many problems that they face, and in order to win this war we must fight our battles in coordination and with dedication.

\section{MILITARY FAMILIES: WHO THEY ARE AND HOW THEY SERVE}

No man is an island. That is, we cannot discuss the issues and challenges affecting servicemembers or veterans without considering their families. The military family can include parents, spouses, partners, siblings, children, grandparents, and other loved ones, who may serve as caregivers to wounded warriors (Calhoun, Beckham, \& Bosworth, 2002). These individuals form an important part of the veteran's support network (Wilcox, 2010) and their health and well-being are directly connected to those of their veteran. That is, a family member's health and wellbeing is also affected by the stressors and challenges in the veteran's life (Bride \& Figley, 2009; Chandra et al., 2010; Lester et al., 2012; Sheppard, Malatras, \& Israel, 2010).

The dynamic relationship continues throughout the servicemember's career and can last beyond separation from the military. Military families also have the unique challenge of "serving with their servicemember." For example, while a servicemember is deployed to a combat zone, their family often worries about the health and safety of the servicemember, in addition to the added task of redistributing household roles to make up for the absence. Once the servicemember returns home, the military family will need to readjust their mentality and household structure to their pre-deployment status, which can often be difficult, particularly for the non-military spouse. Finally, after separation from the military, and throughout the servicemember's career, military families will often relocate and re-adjust to their new home, and develop a civilian family pattern (Pincus, House, Christensen, \& Adler, 2001).

\section{BEYOND THE HOMECOMING: THE REINTEGRATION WAR}

Many of the Reintegration War challenges that veterans and their families experience are similar to those in the civilian world. However, military populations have added unique challenges that may be affecting both veterans and their families, including military-related psychological trauma, military-related physical injuries, unique rules and regulations within the military, social stigma, lack of understanding in the community, lack of access to resources in the community, single parenthood, divorce, unemployment, lack of support for children, and other factors that make life less predictable and controllable. These circumstances, challenges, and problems affect veterans and their families, and hinder their reintegration into the civilian community. This section will describe some of the challenges veterans and their families face in the Reintegration War.

\section{Frequent Relocation}

In a typical military career, servicemembers and their families will relocate every 3-4 years, often across the country and sometimes internationally. These frequent relocations impose additional stressors for the entire family and force them to transition into a new life at a new military installation. Quite often, military installations are not located in the most desirable locations, and it is often difficult to find good schools for children and 
employment for the spouse. In addition to the typical family disruptions, relocations can lead to feelings of alienation and lack of community identification (Burrell, Adams, Durand, \& Castro, 2006; Burrell, Castro, Adler, \& Britt, 2006; McKain, 1973), particularly among those who live off-base. Military families who are able and choose to live on base have the opportunity to live within a supportive community that understands the unique needs of military families.

When they are connected to the military, servicemembers and their families usually maintain close ties to the base and its support services and schools. Once they separate from the service and reintegrate into the civilian world, however, veterans and their families can feel adrift and unsure about where they could seek support or help, especially if they move to an unfamiliar town or another state.

\section{Lack of Access to and Utilization of Resources for Veterans and Military Families}

It can be difficult to navigate through the maze of resources available for military populations (Weinick et al., 2011). Despite the many support services available for veterans and their families, it can be frustrating go to through the process of filing for government services or discouraging to search for help or support in their community. Sometimes, especially in rural areas, veterans do not have access to a Veterans Affairs (VA) office and civilian services are not available. In urban areas, an overabundance of service choices can be overwhelming and confusing, and as more servicemembers separate from the military and move to these areas, both government and community service organizations can also become overwhelmed by veteran needs (Weinick et al., 2011).

Although veterans or families who persist in searching for help or support may find an available service, they are often confronted by well-meaning but uninformed providers who do not understand the scope of the challenges they face as military-impacted individuals. This is a significant barrier to care when we consider that many servicemembers and veterans harbor a stigma against seeking help, especially mental healthcare, and might become so frustrated by a provider's ignorance of military culture and understanding of reintegration challenges that they discontinue treatment (Bryan \& Morrow, 2011; Kim, Britt, Klocko, Riviere, \& Adler, 2011; McFarling, D'Angelo, Drain, Gibbs, \& Rae Olmsted, 2011; Vogt, 2011; Weinick et al., 2011).

\section{Single Parenthood and Divorce among Servicemembers}

The levels of stress present in military marriages often lead to separation and divorce. Research indicates that those who serve in the military often marry earlier and divorce earlier (Hogan \& Seifert, 2010; Karney \& Crown, 2007). The divorce rate among military-connected couples has risen steadily since 2001, and once separated from the military both veteran men and women have a higher divorce rate than comparable civilians (Karney \& Crown, 2007).

The divorce rate for female servicemembers is 2-3 times higher than that of their male counterparts (Karney \& Crown, 2007). Female servicemembers may deal with issues related to family role reversal, separation from their children, and instability in 
their marriages. In American culture, women are typically responsible for household management, are primary caregivers for children and aging parents, and are more likely to face overwhelming expectations upon their return home and reintegration into the community and their family life (Coltrane, 2000). Single parents, many of them mothers in the military, have the added stress of finding caregivers for their children while they deploy, another family transition that adds to the difficulties of reintegration and redeployment (Kelley, Herzog-Simmer, \& Harris, 1994).

Interestingly, research indicates that it does not matter whether the deployed parent is the father or the mother, as both have equal effects on child behavior (Kelley et al., 1994). Thus, deployments and the military life, in general, are stressful and challenging for both male and female servicemembers, although the challenges to the female servicemember can be even more difficult.

\section{Unemployment among Veterans}

In the coming years, as the wars in Iraq and Afghanistan come to an end and the military budget declines, up to a million servicemembers in their prime working years are expected to separate from the military. This large group of separating servicemembers will need to find employment in the civilian job market. The rate of unemployment among veterans is on the rise and is expected to increase as more veterans enter the civilian workforce. The 2011 unemployment rate among post-9/11 veterans who served active duty was 12.1\% (Bureau of Labor Statistics, March 20, 2012), which was higher than the average national unemployment rate for 2011 of 8.95\% (Bureau of Labor Statistics, 2012).

Many veterans will have difficulty finding employment with companies that likely do not understand how their skills translate into the civilian work environment. On top of this, veterans also face the common misperception that all veterans suffer from PTSD or have some mental health problem that will not make good or reliable employees. In fact, over $80 \%$ of recent servicemembers have no reported mental health conditions (Hosek, 2011). Honorably discharged veterans often possess excellent leadership skills that translate well into the civilian work environment, in addition to experience working in

diverse work environments. It will be important to ensure employees are aware of the benefits of hiring veterans and that veterans are aware of ways to translate their military skills into a civilian context.

\section{Lack of Support for Military Children}

Military children face many challenges and destabilizing events unique from their civilian peers. They typically cope with the stress of their active duty parent's absence due to training or deployment, in addition to the fear of loss and worry for their active duty parent's safety. Furthermore, military children often face challenges of reintegrating into a new military installation and school system every 3-4 years, which can disrupts their social ties, academic career, and daily routine. Military children who have had one parent deploy to either Iraq or Afghanistan are more likely to be diagnosed with mental health problems, which increases with increased length of deployments (Mansfield, 
Kaufman, Engel, \& Gaynes, 2011). Those whose parents return with mental health problems or injury face even more stress at home and are more likely to experience problems of their own at home or at school. Military family members, including military children, are also susceptible to secondary traumatic stress (Galovski \& Lyons, 2004; Herzog, 2008).

When their home life is disrupted due to a parent deploying or returning home, a military child's most stable environment is usually his/her school. However, most teachers and school administrators have never been trained in how to respond to or handle students with parents who are serving in the military. Without support from the school, military-connected children are at increased risk of school violence, substance use, suicide, and dropping out of school (Chandra et al., 2010; Gorman, Eide, \& HisleGorman, 2010; Lester, Leskin, et al., 2011; Lester, Mogil, et al., 2011).

These findings highlight the need to ensure school teachers and administrators identify military children and know how to help them. Additionally, it is important to ensure that children are receiving appropriate services to help prevent mental and behavioral problems related to a deployed parent.

\section{Challenges among Reserve and National Guard Members}

Reserve and National Guard members are generally similar to active duty forces, but are slightly older and more educated (Department of Defense, 2010). Reserve and National Guard members typically have a part-time commitment to the military. However, in recent years, more Reserve and National Guard members are being called to active duty, often to complete a deployment in a combat location.

Reserve and National Guard members are disproportionately at risk for mental health problems, with reservists more likely to need mental healthcare services following deployment (Schell \& Marshall, 2008; Werber et al., 2008). Reserve and National Guard members face the added challenges of the frequent civilian-military-civilian transition and are often a long distance from a military installation, thus resulting in more difficulty accessing services and having a supportive environment (Werber et al., 2008). Thus, it is important to help ease the civilian-military-civilian transition for Reserve and National Guard members and their families to help ensure more positive adjustment.

\section{Physical and Psychological Injuries}

Due to advances in combat medicine, more servicemembers with disabling injuries are returning home than ever before. Physical wounds suffered in combat include loss of limbs, facial wounds, burns, hearing damage, and traumatic brain injury (TBI), principally from explosions of roadside bombs or improvised explosive devices (IEDs). Wounds such as these are debilitating, at least to some degree, and can require long periods of reconstructive surgeries, rehabilitation, clinical therapy, as well as long-term care by the spouse or a family member, such as a parent. Injuries such as TBI are additionally challenging because they can be difficult to diagnose and treat, especially if a veteran has trouble establishing the injury with the VA and receiving disability benefits 
or health coverage for treatment (Weinick et al., 2011). Any of these injuries, however, is a significant stressor on a veteran's life and that of his/her family.

The invisible wounds of war, psychological responses to stress, typically posttraumatic stress, depression, and anxiety, have at long last been acknowledged by the U.S. Government and general public as legitimate and serious injuries. Symptoms of posttraumatic stress disorder (PTSD) involve three clusters: a) intrusion symptoms, b) avoidance symptoms, and c) arousal symptoms (American Psychiatric Association, 2000). These symptoms not only affect the veteran's quality of life, but that of his/her family members. However, diagnosis and treatment are difficult because servicemembers have little incentive to report symptoms, due to fear of delaying their return home, fear of discharge, or fear of the stigma of mental illness (Kim et al., 2011; Kim, Thomas, Wilk, Castro, \& Hoge, 2010; McFarling et al., 2011; Pietrzak, Johnson, Goldstein, Malley, \& Southwick, 2009).

Although PTSD garners much attention in the realm of combat-related injuries, it is not the only mental health problem that servicemembers and veterans experience. Research estimates that approximately $30 \%$ of servicemembers who deployed to Iraq or Afghanistan suffer from PTSD, depression, or TBI (Tanielian et al., 2008). Depression can impede personal relationships and career advancement, and cause emotional and financial stress in the family, while suicide attempts in particular produce complicated grief and guilt among surviving family members and unit members, and may result in life-long impairment requiring long-term care by a spouse or other family member (Institute of Medicine, 2010).

Substance use disorder has been increasing in recent years among military servicemembers and recent veterans (Department of Defense, 2011). Returning servicemembers are at increased risk for self-inflicted and other-directed harms, including tobacco use, hazardous drinking, drug use, and accidental overdose. Veterans and their family members who do not utilize treatment for mental health problems are at risk for self-medicating symptoms with alcohol or substances, which can further impair their reintegration and damage their personal relationships and financial security. Unfortunately, like other psychological problems, treatment for substance use disorder also carries the burden of stigma associated with treatment (Rae Olmsted et al., 2011).

\section{Military Sexual Trauma (MST)}

Female servicemembers, who make up approximately $15 \%$ of military forces (Department of Defense, 2010), have high exposure (20-40\%) to sexual assault during their service, known as military sexual trauma (MST) (Kelly, Skelton, Patel, \& Bradley, 2011). MST also occurs in male servicemembers, but at a lower rate. However, the impact of MST is significant for both male and female servicemembers. Sexual harassment and assault under deployment conditions are associated with a five times greater risk of developing PTSD among female servicemembers and six times greater risk of developing PTSD among male servicemembers, a higher risk than combat itself confers (Kang, Dalager, Mahan, \& Ishii, 2005). These traumas are unique to the military experience, as the resulting diagnoses can include an element of "moral injury," a 
violation of values and/or a betrayal of trust, which is caused by the assailant's betrayal of the victim's trust and expectation of protection from fellow servicemembers.

\section{SUMMARY}

The challenges described above are not a comprehensive list of the Reintegration War challenges that servicemembers, veterans, and their families are facing. However, this list of challenges illustrates the broad scope of issues that we must consider when we seek to support or advance reintegrating veterans and their families. It is imperative that we, as family members, service providers, educators, employers, and community members, not only be fully cognizant of this scope of reintegration issues, but also be aware of how these issues reverberate through the veteran's support network. In order to advance a comprehensive effort to strengthen the reintegration of veterans and their families into the community, we must communicate and cultivate a broader and deeper understanding of these issues within all levels of our society and government - on neighborhood, local, state, and national levels.

\section{Our Challenge}

The lack of quality care and support for reintegrating veterans and their families is a significant issue because the strength and viability of our all-volunteer force is undermined when the health and well-being of its members and veterans is so precarious. Hundreds of thousands of servicemembers returning from Iraq and Afghanistan are projected to develop both visible and invisible wounds of war (Institute of Medicine, 2010; Tanielian et al., 2008). Additionally, all of these veterans and their family members are currently reintegrating into their communities or will be over the next several years. These are daunting numbers, which are complicated by the low access to and utilization of services, and even the low levels of military cultural competency among providers. Recent research indicates that veterans were often unaware of available services, were unsure of whether the service would be helpful for their specific problems, lacked information about service locations, were uncertain of eligibility requirements, and did not know how to apply (Schell \& Tanielian, 2011).

Despite recent efforts to increase access to appropriate care for veterans, veterans often encounter a civilian environment ill-prepared to accommodate them and their families due to a lack of understanding about the many challenges and issues that military-impacted individuals face. This shortcoming can be detrimental to the health and well-being of veterans and their families, especially if it discourages them from seeking the care or help they require.

Let us pause here for a moment to acknowledge that there is no silver bullet. The challenges of reintegration encompass such a multitude of factors and actors that no organization is or can be a one-stop shop for the needs of veterans and their families. Each organization, be it a government department, non-profit organization, or local agency, has unique strengths and skills, and all of us must coordinate in order to accomplish the mission: to help veterans and their families reintegrate into the community. 


\section{HOW TO WIN}

Let us examine how we can accomplish this mission. Given the daunting reintegration challenges and associated issues facing our servicemembers, veterans, their families, and our communities, it is essential that government agencies, nongovernmental organizations, and professionals work together to create a model of public-private partnership that will enhance the care and services provided to veterans and their families.

To begin, we must first fill the fundamental gap in our knowledge about the needs of reintegrating veterans and families and the experiences of those who use these systems to access help and resources, as well as research and learn about the best treatment practices that we can apply to these individuals. Then, we need to identify our service capabilities. Since none of us can fill every need of military-impacted populations, we must each identify the specific needs or issues that we are best equipped to handle. Next, we must coordinate our response to the needs of veterans and their families by creating an integrated cooperation and referral system, which will facilitate timely access to competent and capable treatment and services.

\section{Identify Needs}

In the United States, where there is no universal conscription, the gap between civilian and military culture is significant. The U.S. military has its own distinct culture, and as in all cultures, it has developed its own language, symbols, norms, systems for rewards and punishment, and internal institutions to reinforce expectations. The insularity of military culture promotes unity and resilience for the rigors of war, but it can also leave servicemembers and their families less equipped and less comfortable in a civilian environment. At the same time, the widespread lack of understanding of military culture means that community behavioral health providers and other professionals are less effective in communicating with servicemembers, veterans, and their families, less prepared to recognize the constraints they face, and less able to choose interventions or approaches that are helpful.

This shortcoming is significant because, for example, while military ethical standards and traditions are respected in principle by the civilian community, they carry added meaning not always recognized in a therapeutic encounter and can alter the success or failure of a therapeutic alliance. A veteran or family member who seeks out help can be dissuaded from pursuing treatment or assistance if the provider is not familiar with their most basic values and the constraints of their lifestyle. The general lack of understanding regarding military culture and its significance is the first gap in knowledge that every individual and organization that serves military-impacted populations must bridge. In addition, more research is needed on the effect of military culture on the lives of servicemembers, veterans, and their families across all demographics and military service requirements, especially regarding the effect that these factors have on reintegration.

In 2009, to address this gap in knowledge, the School of Social Work at the University of Southern California established the first-ever graduate Military Social Work specialization in a major civilian research university and created the USC Center 
for Innovation and Research on Veterans \& Military Families (CIR), which strengthens the transition of veterans and their families into the community. CIR's creation was driven by our recognition of the critical and emergent need for qualified community providers to treat community-dwelling veterans and their families and rigorous applied research highlighting the challenges faced by, and unique strengths of, military-impacted populations.

At CIR, we leverage the unique educational and research resources of the University of Southern California to optimally serve the nation's veterans and their families by conducting practical research that informs policymakers and deepens the understanding of the obstacles faced by returning veterans and their families. This research informs the Military Social Work specialization in the Master of Social Work program at the School, as well as the continuing education courses that CIR has developed for behavioral healthcare providers and other professionals who serve or work with military-impacted populations.

\section{Specify Service Capabilities}

The needs and issues relating to reintegration span the entire life spectrum of servicemembers, veterans, and their families, employment, relationships, education, marriage, children, mental and physical health, legal issues, which no single organization can meet alone. If we are to successfully strengthen this population's reintegration into the community, then we must each focus on the functions that we can best perform and cooperate to accomplish the tasks we cannot complete alone.

As an example, CIR is located in Los Angeles and is perfectly positioned to conduct research on the needs and reintegration experiences of military-impacted populations due to the large number of veterans-approximately 1,000,000-living in Southern California. In addition, the U.S. Department of Veterans Affairs estimates that an additional 27,000 veterans migrate to California each year. Finally, Orange County and Los Angeles County combined have the largest concentration of National Guard and Reserve forces anywhere in the country. California, and particularly Los Angeles County, therefore represents a highly significant testing-ground for evaluating and developing new community-based interventions that support positive functioning of veterans in a civilian environment and are socio-culturally adapted for ethnic diversity. For these reasons, one of CIR's strongest contributions to the effort of strengthening the reintegration of military-impacted populations is conducting research that will inform best practices for all service providers.

Furthermore, CIR also contributes on the education and training front, by developing and providing innovative, research-informed instruction to social work students, behavioral healthcare providers, and other professionals that work with military-impacted populations. These providers and professionals are employed by other organizations or agencies whose focus and talent is in competently and efficiently deploying direct services to these populations. 


\section{Coordinate Response}

Finally, it is unlikely that the needs of veterans and their families, as well as the quality and access to care and qualified providers, will be adequately addressed unless local, state and federal agencies join forces. Therefore, we need to create a coordinated approach to supporting and engaging veterans and their families by bringing together our diverse sets of resources and identifying new opportunities across the public and private sectors.

To begin with, we must achieve greater coordination between the Department of Defense, the Veteran's Health Administration, and civilian health agencies in transferring patient records, sharing knowledge of efficacious and effective interventions, developing a competent workforce, and building community collaborations to serve veterans and their families. In the past, military and civilian services for veterans existed on parallel tracks, but today they are intertwined as never before, driven together out of necessity to address the widespread phenomenon of homelessness, drug abuse, and mental illness among Vietnam veterans. Local mental health clinics, school mental health programs, hospital emergency rooms, and other mental health-affiliated agencies are vital to providing care and support to veterans and their families. Therefore, these civilian providers will require an understanding of the needs in military-impacted populations as well as facilitated access to their medical records, held by military or government agencies.

Next, a coordination effort is required to bring diverse resources together in order to identify new opportunities to cooperate across public and private sectors and develop approaches to providing care and support to veterans and their families. This coordination effort must be based in and informed by the needs of the local community, but also supported at the state level. As a Southern California institution, CIR maintains connections with hundreds of community care and healthcare organizations in the region, and connects them with its local, regional, and national partners in order to advance solutions in research and care for military-impacted populations. Similarly, each region of the country needs an entity that can facilitate the connections, organization, and dissemination of information necessary to coordinate community response to the needs of local military-impacted populations and promote these needs and the needs of the service providers on both a state and national level.

\section{CONCLUSION}

No one comes home from war unchanged. For some, leaving the combat zone marks the beginning of a new battle - to reconcile the emotional changes that have resulted from their experiences, to smoothly reunite with their families, to put the stresses of combat behind them, and to find employment that fulfills them and utilizes the skills they have gained. Many veterans and their family members need expert assistance in rebuilding their lives, and it is our responsibility to support them. In order to adequately respond to the needs of veterans and their families and strengthen their reintegration into the community, we must all join together and operate as a single unit-a collection of 
capable organizations and individuals, each with specific focus areas and tasks. Only together, and with each other's help, will we accomplish this important mission.

\section{References}

American Psychiatric Association. (2000). Diagnostic and statistical manual of mental disorders: DSM-IV-TR. Washington, DC: American Psychiatric Association.

Belasco, A. (2009, July 2). Troop Levels in the Afghan and Iraq Wars, FY2001-FY2012: Cost and Other Potential. (R40682). Congressional Research Service.

Bride, B. E., \& Figley, C. R. (2009). Secondary trauma and military veteran caregivers. Smith College Studies in Social Work, 79(3-4), 314-329. doi: 10.1080/00377310903130357

Bryan, C. J., \& Morrow, C. E. (2011). Circumventing mental health stigma by embracing the warrior culture: Lessons learned from the Defender's Edge program. Professional Psychology: Research and Practice, 42(1), 16-23. doi: 10.1037/a0022290

Bureau of Labor Statistics. (2012). Databases, Tables \& Calculators by Subject: Labor Force Statistics from the Current Population Survey. Retrieved from http://data.bls.gov/timeseries/LNS14000000

Bureau of Labor Statistics. (2012, March 20). Employment Situation of Veterans Summary 2011. Retrieved from http://www.bls.gov/news.release/vet.nr0.htm

Burrell, L. M., Adams, G. A., Durand, D. B., \& Castro, C. (2006). The Impact of military lifestyle demands on well-being, Army, and family outcomes. [Article]. Armed Forces \& Society (0095327X), 33(1), 43-58. doi: 10.1177/0002764206288804

Burrell, L. M., Castro, C., Adler, A., \& Britt, T. (2006). Moving military families: The impact of relocation on family well-being, employment, and commitment to the military. In C. Castro, A. Adler, \& T. Britt (Eds.), Military life (Vol. 3, pp. 39-63). Westport, CT: Praeger Security International.

Calhoun, P. S., Beckham, J. C., \& Bosworth, H. B. (2002). Caregiver burden and psychological distress in partners of veterans with chronic posttraumatic stress disorder. Journal of Traumatic Stress, 15(3), 205-212. doi: 10.1023/a:1015251210928

Chandra, A., Lara-Cinisomo, S., Jaycox, L. H., Tanielian, T., Burns, R. M., Ruder, T., \& Bing, H. (2010). Children on the homefront: The experience of children from military families. [Article]. Pediatrics, 125(1), 16-25. doi: 10.1542/peds2009-1180

Coltrane, S. (2000). Research on household labor: Modeling and measuring the social embeddedness of routine family work. Journal of Marriage and Family, 62, 12081233.

Department of Defense. (2010). Demographics 2010: Profile of the military community. Washington, DC: Department of Defense. 
Department of Defense. (2011). Joint Mental Health Advisory Team 7 (J-MHAT 7): Operation Enduring Freedom 2010, Afghanistan. Washington, DC: Department of Defense Retrieved from http://www.armymedicine.army.mil/reports/mhat/mhat_vii/J_MHAT_7.pdf.

Galovski, T., \& Lyons, J. A. (2004). Psychological sequelae of combat violence: A review of the impact of PTSD on the veteran's family and possible interventions. Aggression and Violent Behavior, 9(5), 477-501. doi: 10.1016/s1359-1789(03)000454

Gorman, G. H., Eide, M., \& Hisle-Gorman, E. (2010). Wartime military deployment and increased pediatric mental and behavioral health complaints. Pediatrics, 126(6), 1058-1066. doi: 10.1542/peds.2009-2856

Herzog, J. R. (2008). Secondary trauma in family members of combat veterans. (2008), University of South Carolina, US. Retrieved from http://gradworks.umi.com/33/32/3332249.html (3332249)

Hogan, P. F., \& Seifert, R. F. (2010). Marriage and the military: Evidence that those who serve marry earlier and divorce earlier. [Article]. Armed Forces \& Society (0095327X), 36(3), 420-438.

Hosek, J. (2011). How is deployment to Iraq and Afghanistan affecting U.S. service members and their families? Santa Monica, CA: RAND Corporation Retrieved from http://www.rand.org/content/dam/rand/pubs/occasional_papers/2011/RAND_OP316. pdf.

Institute of Medicine. (2010). Returning home from Iraq and Afghanistan: Preliminary assessment of readjustment needs of veterans, service members and their families. Washington, DC: The National Academies Press.

Kang, H., Dalager, N., Mahan, C., \& Ishii, E. (2005). The role of sexual assault on the risk of PTSD among Gulf War veterans. Annals of Epidemiology, 15, 191-195.

Karney, B. R., \& Crown, J. S. (2007). Families under stress: An assessment of data, theory, and research on marriage and divorce in the military. Santa Monica, CA: RAND Corporation.

Kelley, M. L., Herzog-Simmer, P. A., \& Harris, M. A. (1994). Effects of militaryinduced separation on the parenting stress and family functioning of deploying mothers. Military Psychology, 6, 125-138.

Kelly, U. A., Skelton, K., Patel, M., \& Bradley, B. (2011). More than military sexual trauma: Interpersonal violence, PTSD, and mental health in women veterans. Research in Nursing \& Health, 34(6), 457-467. doi: 10.1002/nur.20453

Kim, P. Y., Britt, T., Klocko, R. P., Riviere, L. A., \& Adler, A. (2011). Stigma, negative attitudes about treatment, and utilization of mental health care among Soldiers. Military Psychology, 23, 65-81. 
Kim, P. Y., Thomas, J. L., Wilk, J. E., Castro, C. A., \& Hoge, C. W. (2010). Stigma, barriers to care, and use of mental health services among active duty and National Guard soldiers after combat. Psychiatric Services, 61(6), 582-588.

Lester, P., Leskin, G., Woodward, K., Saltzman, W., Nash, W., Mogil, C., Paley, B., \& Beardslee, W. (2011). Wartime deployment and military children: Applying prevention science to enhance family resilience. In S. M. Wadsworth \& D. Riggs (Eds.), Risk and resilience in U.S. military families (pp. 149-173). New York, NY: Springer Science + Business Media.

Lester, P., Mogil, C., Saltzman, W., Woodward, K., Nash, W., Leskin, G., Bursch, B., Green, S., Pynoos, R., \& Beardslee, W. (2011). Families overcoming under stress: Implementing family-centered prevention for military families facing wartime deployments and combat operational stress. Military Medicine, 176(1), 19-25.

Lester, P., Saltzman, W. R., Woodward, K., Glover, D., Leskin, G. A., Bursch, B., Pynoos, R., \& Beardslee, W. (2012). Evaluation of a family-centered prevention intervention for military children and families facing wartime deployments. American Journal of Public Health, 102(S1), S48-S54. doi: 10.2105/ajph.2010.300088

Mansfield, A. J., Kaufman, J. S., Engel, C. C., \& Gaynes, B. N. (2011). Deployment and mental health diagnoses among children of US Army personnel. Archives of Pediatrics \& Adolescent Medicine, 165(11), 999-1005. archpediatrics.2011.2123. doi: 10.1001/archpediatrics.2011.123

McFarling, L., D'Angelo, M., Drain, M., Gibbs, D. A., \& Rae Olmsted, K. L. (2011). Stigma as a barrier to substance abuse and mental health treatment. Military Psychology, 23(1), 1 - 5.

McKain, J. L. (1973). Relocation in the military: Alienation and family problems. Journal of Marriage and Family, 35(2), 205-209.

Pietrzak, R. H., Johnson, D. C., Goldstein, M. B., Malley, J. C., \& Southwick, S. M. (2009). Perceived stigma and barriers to mental health care utilization among OEFOIF veterans. Psychiatric Services, 60(8), 1118-1122. doi: 10.1176/appi.ps.60.8.1118

Pincus, S., House, R., Christensen, J., \& Adler, L. (2001). The emotional cycle of deployment: A military family perspective. Journal of the Army Medical Department, 615-623.

Rae Olmsted, K. L., Brown, J. M., Vandermaas-Peeler, J. R., Tueller, S. J., Johnson, R. E., \& Gibbs, D. A. (2011). Mental health and dubstance abuse treatment stigma among soldiers. Military Psychology, 23(1), 52 - 64.

Schell, T. L., \& Marshall, G. N. (2008). Survey of individuals previously deployed to OEF/OIF. In T. Tanielian \& L. H. Jaycox (Eds.), Invisible wounds of war: Psychological and cognitive injuries, their consequences, and services to assist recovery (pp. 87-115). Santa Monica, CA: RAND Corporation. 
Schell, T. L., \& Tanielian, T. (2011). A needs assessment of New York State veterans: Final report to the New York State Health Foundation. Santa Monica, CA: RAND Corporation.

Sheppard, S. C., Malatras, J. W., \& Israel, A. C. (2010). The impact of deployment on U.S. military families. American Psychologist, 65(6), 599-609. doi: 10.1037/a0020332

Tanielian, T., Jaycox, L. H., Schell, T. L., Marshall, G. N., Burnam, M. A., Eibner, C., . . . Invisible Wounds Study Team. (2008). Invisible wounds of war: Summary and recommendations for addressing psychological and cognitive injuries. (MG-720/1CCF). Santa Monica, CA: RAND Corporation.

U.S. Census Bureau. (2010). Veteran Status: 2010 American Community Survey 1-Year Estimates. Retrieved from http://factfinder2.census.gov/faces/tableservices/jsf/pages/productview.xhtml?pid=A CS_10_1YR_S2101\&prodType=table

Vogt, D. (2011). Mental health-related beliefs as a barrier to service use for military personnel and veterans: A review. Psychiatric Services, 62(2), 135-142.

Weinick, R. M., Beckjord, E. B., Farmer, C. M., Martin, L. T., Gillen, E. M., Acosta, J., . .. Scharf, D. M. (2011). Programs addressing psychological health and traumatic brain injury among U.S. military servicemembers and their families. Santa Monica, CA: RAND Corporation Retrieved from http://www.rand.org/pubs/technical_reports/TR950.

Werber, L., Harrell, M. C., Varda, D. M., Hall, K. C., Becklett, M. K., \& Stern, S. (2008). Deployment experiences of Guard and Reserve families: Implications for support and retention. Santa Monica, CA: RAND Corporation Retrieved from http://www.rand.org/pubs/monographs/MG645.html.

Wilcox, S. (2010). Social relationships and PTSD symptomatology in combat veterans. Psychological Trauma: Theory, Research, Practice, and Policy, 2(3), 175-182. doi: 10.1037/a0019062

\section{Author's note:}

Address correspondence to: Megan Hazle, Center for Innovation and Research on Veterans \& Military Families (CIR), School of Social Work, University of Southern California, 1149 S. Hill Street, Suite H-1114, Los Angeles, CA, 90015. E-mail: hazle@usc.edu 